\title{
Platform to develop exhaust gas sensors manufactured by glass-solder-supported joining of sintered yttria-stabilized zirconia
}

\author{
F. Schubert, S. Wollenhaupt, J. Kita, G. Hagen, and R. Moos \\ University of Bayreuth, Bayreuth Engine Research Center (BERC), Department of \\ Functional Materials, 95440 Bayreuth, Germany \\ Correspondence to: F. Schubert (functional.materials@uni-bayreuth.de)
}

\begin{abstract}
Received: 13 October 2015 - Revised: 30 November 2015 - Accepted: 20 December 2015 - Published: 22 January 2016
\end{abstract}
\begin{abstract}
A manufacturing process for a planar binary lambda sensor is shown. By joining the heating and the sensing components via glass soldering with a joining temperature of $850^{\circ} \mathrm{C}$, a laboratory platform has been established that allows the manufacturing of two independent parts in high-temperature co-fired ceramics technology (HTCC) with electrodes that are post-processed at lower temperatures, as is required for mixedpotential sensors. The final device is compared to a commercial sensor with respect to its sensing performance. Important processes and possible origins of problems as well as their solutions during sensor development are shown, including heater design and joining process.
\end{abstract}

\section{Introduction}

Gas sensors are indispensable parts in modern automotive exhaust gas aftertreatment systems. Driven by stringent emission limits and the need for fuel efficiency and environmental protection, such systems are getting more and more complex. Sensors are required for continuous exhaust gas monitoring to control the combustion process as well as to monitor the conversion of the catalysts (Twigg, 2007).

The most used material in exhaust gas sensing is yttriastabilized zirconia (YSZ). It provides several advantages like relevant functional properties combined with mechanical strength and high temperature stability to address the requirements arising from application in the harsh exhaust environment (Riegel, 2002; Ramamoorthy et al., 2003; Badwal, 1992). Here, sensors have to withstand temperatures up to $1000^{\circ} \mathrm{C}$; poisoning impacts from oils, ashes, or gases; and mechanical vibrations. As an example, the switching-type lambda probe (or binary lambda probe) shall be briefly introduced in the following to illustrate the major challenges in exhaust gas sensing. Both working principle and manufacturing technology are of relevance for this study and are discussed in the following section.
In general, a lambda probe sensor has to monitor the oxygen content which results from the thermodynamic equilibrium of all gases in the exhaust. If there is oxygen excess in the tailpipe emissions, the combustion is called "lean" and the nitric oxides $\left(\mathrm{NO}_{x}\right)$ cannot be converted by classical three-way catalysts (TWCs). In contrast to that, reduced exhaust components (unburned hydrocarbons, HC, or carbon monoxide, $\mathrm{CO}$ ) prevail in the exhaust in the "rich" engine operation mode. The quotient of the actual air / fuel ratio in the combustion to the stoichiometric ratio is called lambda $(\lambda)$. An efficient catalytic conversion of $\mathrm{NO}_{x}$ as well as $\mathrm{HC}$ and $\mathrm{CO}$ in a TWC is only possible when the combustion is controlled to a stoichiometric ratio of $\lambda \approx 1$. The measuring principle of a switching-type lambda probe fits the need to detect deviations from $\lambda=1$. By comparing the oxygen content in the exhaust with that of a reference atmosphere (e.g., ambient air, $p \mathrm{O}_{2} \approx 0.2$ ) via a solid-state oxygen ion conductor, a voltage between exhaust side and reference side can be measured following the Nernst equation. This sensor signal depends directly on the logarithmic quotient of the partial pressures of oxygen in the exhaust and in the reference air. The resulting characteristic curve of the sensor has a binary characteristic. It shows a relatively high voltage of about $1 \mathrm{~V}$ in rich atmospheres (large difference between both par- 
tial pressures), a voltage below $200 \mathrm{mV}$ in lean conditions, and an almost abrupt transition in between, indicating the stoichiometric point. Such sensors are realized in a planar high-temperature co-fired ceramics technology (HTCC), using YSZ green tapes as base material (Baunach et al., 2006; Riegel, 2002). Functional elements such as electrodes and an internal heating element are manufactured via screen printing using high-temperature-stable noble metal platinum as the conductor material. Pt in that case provides the needed electrical as well as catalytic properties and is stable during the high-temperature sintering of the ceramic substrate at a temperature on the order of $1400^{\circ} \mathrm{C}$. The lambda probe is usually operated at about $700^{\circ} \mathrm{C}$ for several reasons: the ceramic carrier must be oxygen ion conducting (the higher the temperature, the better), the sensing electrode - and its covering - must be catalytically active to achieve a thermodynamic equilibrium of all gas components in that local area (the higher the temperature, the better), and soot deposition has to be avoided (soot burns off at about $600^{\circ} \mathrm{C}$ ). The upper operating temperature is limited by the increasing electronic conductivity of the YSZ to about $1000^{\circ} \mathrm{C}$; see for instance Burke et al. (1971).

Altogether, a YSZ ceramic-based sensor combines all advantages for potentiometric exhaust gas sensors. Therefore, the described lambda probe has been well established for more than 40 years in serial application. On that basis, further developments for example of wide-range lambda sensors, $\mathrm{NO}_{x}$ sensors (Brosha, 2002; Kato et al., 1996; Alkemade and Schumann, 2006) or $\mathrm{NH}_{3}$ sensors (Wang et al., 2009) were possible and YSZ became the standard material in exhaust gas sensing.

As mentioned above, future exhaust gas aftertreatment systems are getting more complex, and therefore the need for additional gas sensors in that area is increasing. Furthermore, the use of sensors is unavoidable for on-boarddiagnostic (OBD) purposes required by law. That means, all emission-relevant parts have to be monitored continuously during operation to indicate a malfunction and trigger a warning to the driver. The sensing challenges will be $\mathrm{NO}_{x}$ (distinguishing between $\mathrm{NO}$ and $\mathrm{NO}_{2}$ at its best), hydrocarbons ( $\mathrm{HCs})$, or ammonia $\left(\mathrm{NH}_{3}\right)$. Therefore, other sensing principles, e.g., mixed-potential-based systems (Fergus, 2007; Miura et al., 1998, 2014; Schönauer et al., 2011; Wang et al., 2014; Xiong and Kale, 2006; Zosel et al., 2002), are under study for application in the harsh exhaust environment (Guth and Zosel, 2004; Liu et al., 2014; Ménil et al., 2000). Recent studies deal also with novel approaches like pulse polarization methods (Fischer et al., 2010) or direct conversion rate sensors (Hagen et al., 2015a).

The major problem of all these principles is the need to use other electrode materials. In mixed-potential applications, complex alloys, metal-oxide cermets, etc., are of interest (Moos et al., 2009; Miura et al., 2014; Zosel et al., 2004; Zhuiykov and Miura, 2007). Such materials may be long-term stable in exhaust atmospheres. But mostly, it is not possible to integrate them into an HTCC setup due to the required high sintering temperatures. Gold for instance, which serves as an electrode in a classical YSZ-based mixedpotential sensor, has a melting point of $1064^{\circ} \mathrm{C}$ and cannot be co-fired with zirconia at (typical sintering temperatures of) $1400^{\circ} \mathrm{C}$.

The aim of this contribution is to establish a YSZbased sensing platform which overcomes this drawback. We present a possibility to manufacture a planar switching-type lambda probe made of two separate produced parts, which are joined together by the new process at moderate temperatures of about $850^{\circ} \mathrm{C}$. This offers the integration of "low" sintering complex electrode materials inside the sensor element (which can be, e.g., in contact with the reference atmosphere).

As the first step we present the manufacturing process for a monolithic sensor device, reproducing the state of the art of a planar switching-type lambda probe. All parts of the sensor are processed in the green state, laminated together and sintered in one step. Here, we could identify the "crux of the matters", meaning key aspects in processing vias, conduction paths, electrical insulation of the heater, lamination parameters, and the firing profile. As a constant temperature is important for accuracy of certain measurement principles (Mahendraprabhu et al., 2013), we integrated a four-wire heating structure that can be controlled to a certain temperature by its four-wire resistance.

For the second part of the work, we divide up the manufacturing process: two parts of the sensor were sintered separately and joined together with a glass ceramic material using lower sintering temperatures. Finally, we compare the "joined" lambda probe with a commercial device in a measurement.

With this setup, a laboratory platform has been established that allows two independent parts to be manufactured in HTCC technology. Later the top side can have electrodes that are post-processed at lower temperatures. As the final step, both parts are joined together at $850^{\circ} \mathrm{C}$.

\section{Design and modeling of the new sensor}

For better understanding and optimization of the HTCC fabrication process, a switching-type lambda probe was designed in the first step (Fig. 1). The sensor can be divided into the following parts: heater base with the contact pads, where the heater, which was covered by alumina insulation layers, is deposited; heater cover; part with the reference channel; and electrolyte part with screen-printed platinum electrodes on both sides. Each part contains a different number of zirconia layers. Thus the thicknesses of different functional elements can be varied: the thickness of the heater base is $0.4 \mathrm{~mm}$, the heater cover is $0.3 \mathrm{~mm}$, the reference channel is $0.1 \mathrm{~mm}$, and the electrolyte is $0.1 \mathrm{~mm}$ thick. 


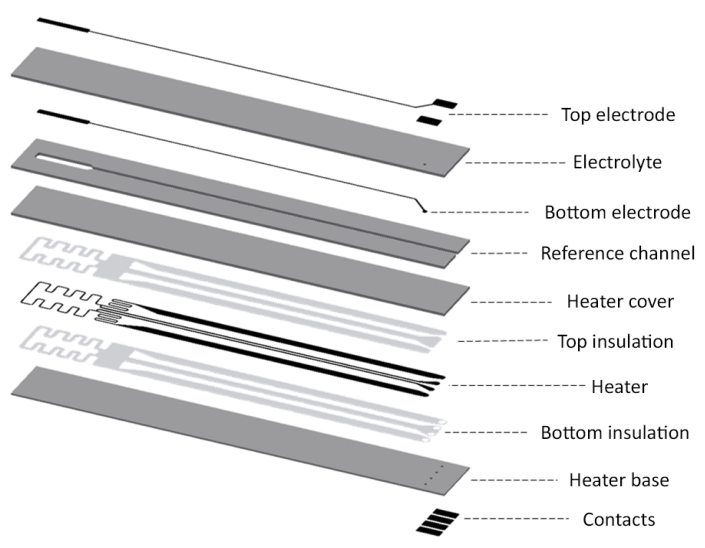

Figure 1. Exploded view of the sensor.

The construction of the heater requires special attention in the here-presented application. The heater should exhibit a homogeneous temperature distribution to maximize the sensor response. Because of the special properties of zirconia, the heater has to be insulated for blackening reasons (Janek, 1999). Therefore, it was insulated from both sides using an alumina thick-film layer. Moreover, we decided to use a fourwire solution. Thus, the precise control of heater resistance and its temperature is possible during heating.

The first design of the heater structure drew upon heater design experience from previous work by Kita et al. (2005). Before realizing the structure, the geometry was optimized using COMSOL Multiphysics ${ }^{\circledR}$. Properties of materials in the model were fitted to the commercial tape system of Electroscience Lab (ESL) that was chosen for fabricating the sensor (ESL, 2015). It contains all required materials for producing a planar sensor structure, including the $5 \mathrm{~mol} \%$ yttriastabilized zirconia tape, an aluminum insulator paste, a platinum conductor paste for the heater and filling vias, and a cermet paste for the electrodes. A sacrificial tape, which is proven to help maintain dimensional stability of the reference channel, is also part of the system (Khoong et al., 2010).

Special attention has been given to the temperature dependency of material data, as stressed by Kita et al. (2015). Therefore, at first the thermal conductivity of zirconia was measured using the LFA 1000 Laser Flash Apparatus (Linseis Messgeräte GmbH, Selb, Germany). Other data for thermal conductivity were taken from the VDI Heat Atlas (2010).

Boundary conditions were applied as follows:

- The contact area of the sensor-surrounding temperature was set to $100^{\circ} \mathrm{C}$ as the sensor was to be screwed into a heated pipe for testing.

- Boundary conditions for natural convection were applied according to the VDI Heat Atlas (2010).

- Additionally, a thermal radiation was defined with emissivity according to Tanaka et al. (2001).

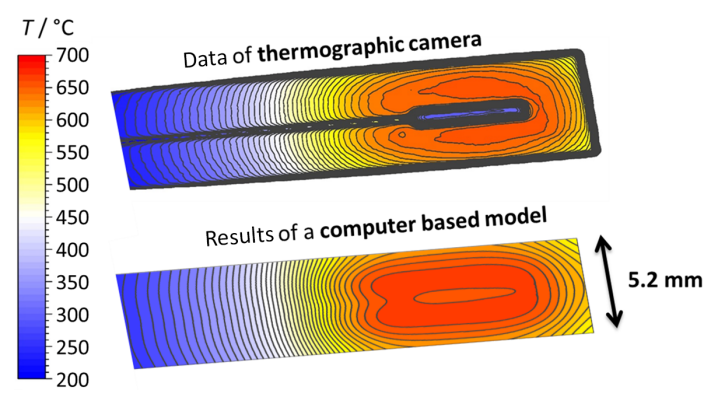

Figure 2. The temperature distribution as calculated by the FEM model and compared with data obtained by infrared camera.

The optimization results are shown in Fig. 2. The model shows the uniform temperature distribution within the heater. The temperature of the electrode is about $660^{\circ} \mathrm{C}$, with a temperature uniformity better than $10^{\circ} \mathrm{C}$.

After preparation of initial samples, the results of the simulation were compared with an infrared camera measurement of a heated sensor. The outer electrode can be clearly seen due to the lower emissivity of the platinum/cermet paste. The temperature distribution is also in the range of $\pm 5^{\circ} \mathrm{C}$. However, the area of uniform temperature distribution is about $2 \mathrm{~mm}$ shorter. This may be a result of the measurement conditions - the sensor had to be measured without protective cover. This increases the convection around the sensor and lowers the temperature of the surrounding gas compared to the model. Nevertheless, the obtained simulation results agree with the data measured in the real samples.

\section{Fabrication of the sensor}

Platinum structures were screen-printed on unfired YSZ tapes using 325 mesh screens (platinum) or 200 mesh screens (alumina). The widths of the conductor lines in the heater structure were $150 \mu \mathrm{m}$; the widths of the feed lines were about $0.9 \mathrm{~mm}$. The insulation for alumina was printed twice to ensure sufficient density of the layer. The alumina layer was set to be $150 \mu \mathrm{m}$ broader than the conduction paths to allow for some tolerance in the printing process. The reference channel was laser-structured. Heater contacts were deposited on the reverse side of the heater base.

The embedded heater is connected to the contacts on the reverse side of the sensor using vias. Similarly, one of the electrodes on the top needs to be connected by vias. To ensure functionality of the sensor, the vias should be reliably produced. Therefore, a test of the via-filling process was conducted. Pre-laminated green sheets with laser-cut vias were placed on a porous ceramic plate. Vacuum was applied, which caused the deposited paste to be sucked into the via. Two different via-filling methods were tested. In the first attempt, the vacuum was kept low to prevent paste smearing out from the vias at the other side and contaminating the reverse side of the laminate. The vias were filled from both 


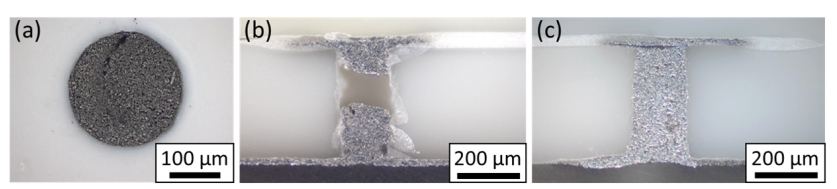

Figure 3. Top view of an unsintered filled via (a), cross section of a sintered via filled from both sides (b), cross section of a sintered via repeatedly filled from one side (c).
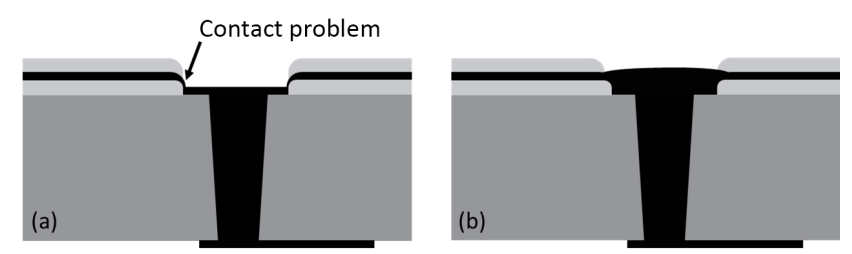

Figure 4. Contact between via and conduction path without (a) and with (b) additional paste applied.

sides of the laminate. In the second test, the vacuum was increased and the vias were filled repeatedly from one side. Afterwards the residual paste was removed.

Via-filling results are shown in Fig. 3. Generally, filling of the vias in unfired tapes or laminates is more difficult than the via-filling process known from conventional hybrid thick-film technology (Ortolino et al., 2011). The main problem is that, when filling the laminated green sheets, solvents of pastes diffuse rapidly into the green sheets and the paste dries out before filling is completed. Thus, paste from the first attempt very often clogged the via openings and hindered vacuum suction and thus prevented filling the second part of the via. Whereas the via seems to be completely filled (Fig. 3a), the cross section shows unfilled regions (Fig. 3b). Repeatedly filling from one side seems to be a better solution (Fig. 3c). In the first filling procedure, the via walls are covered; in the further steps the vias can be completely filled to achieve full density.

As important as vias are also their connections to the conductive lines. After screen printing of conductive lines, some problems were observed at the edges of the alumina insulation. For a better understanding, the problem was sketched in Fig. 4a. It was found that the relatively thin platinum line placed between thick alumina layers is exposed to high stress during lamination, and the contact between via and conductive line can break up. However, this can easily be remedied when applying an additional drop of paste on top of the vias, as shown in Fig. 4b.

To further increase reliability, the conduction paths have to be improved. The screen-printed alumina layer is generally very rough. Therefore, the minimal line width of the platinum lines should be at least $200 \mu \mathrm{m}$ when printed on the dried alumina layer.

One of the key steps to form structural integrity of the sensor is the lamination process. As initial cracks in the ceramic (a)

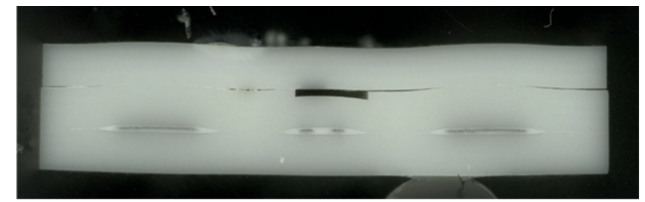

(b)

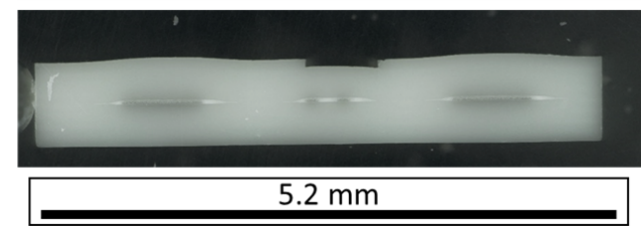

Figure 5. Cross section of a sintered sample with an electrolyte sheet pressed for $12 \mathrm{~min}$ at $20 \mathrm{mMPa}$ (a) and a sample without electrolyte sheet pressed for $20 \mathrm{~min}$ at $25 \mathrm{MPa}$ (b).

are detrimental to its strength, special care has to be taken to minimize them, especially in those areas of the heater with its insulation layers.

Generally, two lamination techniques are possible (Imanaka, 2005). For forming cavities, uniaxial pressing is preferred, as the compression of material occurs only on the $z$ axis, where no cavity is to be found between the pressing tools. Thus, cavities can be realized without use of a sacrificial layer if the heater is pre-laminated (Rabe et al., 2007). The other type of lamination is the isostatic one. As the sample is laminated in a liquid, pressure and temperature will be distributed uniformly and thus compensate for the unevenness of the sample. For this reason, isostatic pressing was selected for our experiments. However, when applying this process, cavities have to be filled with a sacrificial tape, which is an additional step of work.

To improve tape handling, each single sensor part was pre-laminated prior to screen printing. Parts with a reference channel and parts with a heater were separately prelaminated at $10 \mathrm{MPa}$ and $70^{\circ} \mathrm{C}$ for $10 \mathrm{~min}$. Applying a relatively low pressure causes single tapes to stick together without achieving final density and stability, meaning that both parts can be further laminated together. Lamination for $12 \mathrm{~min}$ at $20 \mathrm{MPa}$ or $20 \mathrm{~min}$ at $25 \mathrm{MPa}$ and firing at $1550^{\circ} \mathrm{C}$ in a chamber furnace concluded the ceramic process.

Figure 5a shows a cross section of the sintered sensor. Whereas the lamination at the plane of the heater, covered by alumina layers, is very good, lamination of the electrolyte part on an uneven heater required further improvement.

The delamination is visible not only at the edges of the structure but also in the area of the reference channel. The electrolyte sheet made contact only at the protruding areas of the heater. We found that the best results can be achieved if the lamination is divided into three parts: pre-lamination prior to printing, lamination of the heater, and lamination heater and reference channel. When time and temperature of the lamination process were increased, best results were achieved for the heater sheets (Fig. 5b). However, the sacrificial tape in the reference channel is not able to withstand the 


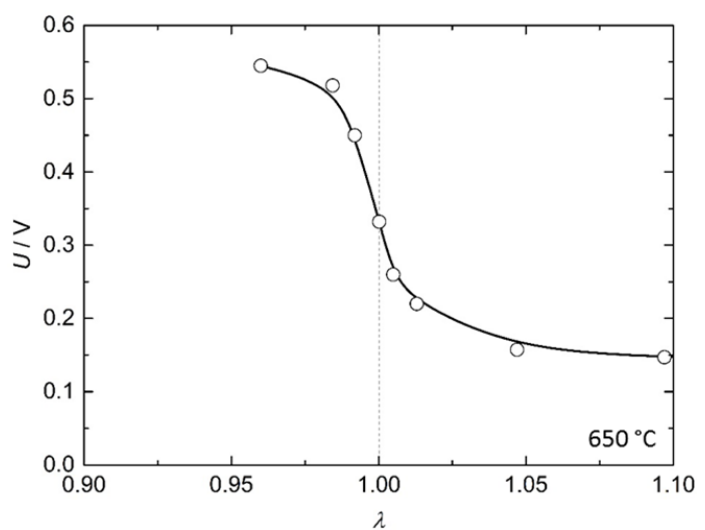

Figure 6. Response of a one-step sintered sensor to lambda variations around the stoichiometric point.

pressure and collapses. One solution can be to reduce the insulation layer size and thereby improve the lamination characteristics.

\section{First measurement}

The prepared one-step sintered sensor was measured at $650^{\circ} \mathrm{C}$. Prior to the measurement, the characteristic curve of the heater temperature vs. the heater resistance was calibrated with a pyrometer. During the measurement, the temperature of the sensor was controlled by the heater resistance. A digital multimeter (Keithley 2700) was used to log the potentials between the electrodes. The gas atmosphere contained $\mathrm{CO}, \mathrm{H}_{2}, \mathrm{H}_{2} \mathrm{O}$, and $\mathrm{N}_{2}$ with varying $\mathrm{O}_{2}$ contents to adjust $\lambda$. A commercial ETAS Lambda Meter was used to measure the $\lambda$ values. The sensor was mounted onto a gas test bench. To achieve a gas-tight sealing, it was cast integrally into a stainless-steel tube by use of an epoxy resin. A catalyst was applied by brush coating on the electrode surface with a thickness of about $100 \mu \mathrm{m}$ to establish the equilibrium even further. The catalyst coating was prepared by impregnating porous $\mathrm{Al}_{2} \mathrm{O}_{3}$ powder (Baikowski CR10, BET specific surface area: $7 \mathrm{~m}^{2} \mathrm{~g}^{-1}$; agglomerate size $d_{90}$ : $1.25 \mu \mathrm{m}$ ) with platinum in the form of the platinum complex $\left[\left(\mathrm{NH}_{3}\right)_{4} \mathrm{Pt}\right] \mathrm{Cl}_{2} \cdot \mathrm{H}_{2} \mathrm{O}$ (Sigma-Aldrich). The platinum complex was dissolved in deionized water, and the alumina was mixed into the solution, with a mass ratio of $100: 1$ ( $\left.m_{\text {alumina }}: m_{\text {platinum complex }}\right)$. Finally, the powder was reduced in a vertical reactor at $500^{\circ} \mathrm{C}$ for $1 \mathrm{~h}$ under forming gas $(5 \%$ $\mathrm{H}_{2}$ in $\mathrm{N}_{2}$ ). For coating, the catalyst was processed to a paste by mixing it with terpineol and ethyl cellulose as an organic binder. The exact properties of the catalyst were determined by Hagen et al. (2015b). Measurements of the sensor are shown in Fig. 6.

The sensor exhibits the desired lambda switch, characterized by the drop of the signal when the partial pressure of oxygen rises over several decades as the atmosphere changes

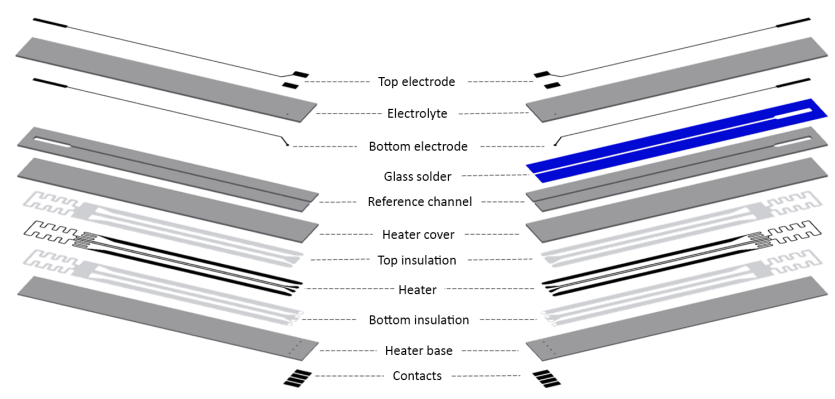

Figure 7. Exploded view of the sensor without (left) and with (right) glass-soldering layer.

from rich to lean. The sensor shows a relatively low signal and an offset in the lean area. Further upcoming work will address these issues. However, the general function of the sensor was proven by this test.

\section{Joined sensor}

Since the results of the one-step sintered sensors were very promising, a modular platform was fabricated in the second step. As mentioned above, such a platform can be utilized to build ample different sensors. To join the two parts of the sensor, we chose a layer of joining glass, a material formulation that has been described by Dev et al. (2014) and Lessing (2007).

For enhanced clarification, the new design is depicted in Fig. 7. The difference between both depicted structures can be seen in the glass-soldering paste that joins the Nernst element to the reference channel instead of sintering them together.

For fabrication of the joining glass paste two different types of glass powder were taken into account (type A and type $\mathrm{B}$ ). The glass transition point $T_{\mathrm{G}}$ for type $\mathrm{A}$ was around $660^{\circ} \mathrm{C}$ and for type $\mathrm{B}$ around $600^{\circ} \mathrm{C}$. Both powders were sieved with a mesh width of $90 \mu \mathrm{m}$ to remove the coarsest particles. Additionally, the glass powder was dried at $80^{\circ} \mathrm{C}$ for $8 \mathrm{~h}$.

The solder in the form of a thick-film paste was obtained by mixing commercial recrystallizing glass powder with the thermal expansion coefficient (TCE) adjusted to YSZ ceramics with a binder made of ethyl cellulose and terpineol (ratio $1: 11$ ) using a three-roll mill (EXAKT).

The prepared paste was screen-printed and leveled for $15 \mathrm{~min}$. In first experiments, the paste was not dried before both sides were joined so that the capillary force could reduce the space between the surfaces and compensate for flatness imperfections that may arise during joining. When the parts adhered, the sensor was dried at $100^{\circ} \mathrm{C}$ for $2 \mathrm{~h}$.

Type A was sintered at $1000^{\circ} \mathrm{C}$ for $15 \mathrm{~min}$, and type B was sintered for $15 \mathrm{~min}$ at $850^{\circ} \mathrm{C}$. Both samples were weighted down to improve adhesion. The resulting samples were cut with a diamond saw and polished to investigate the joining 
(a)

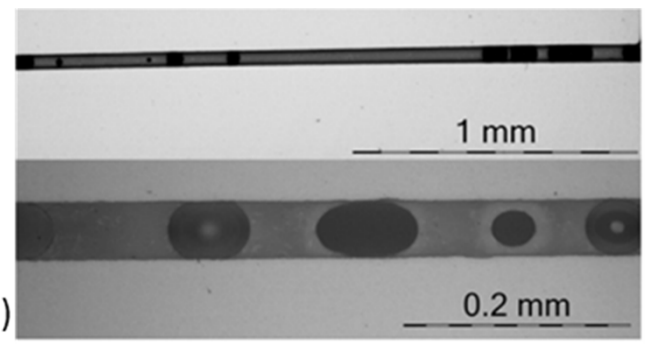

(b)

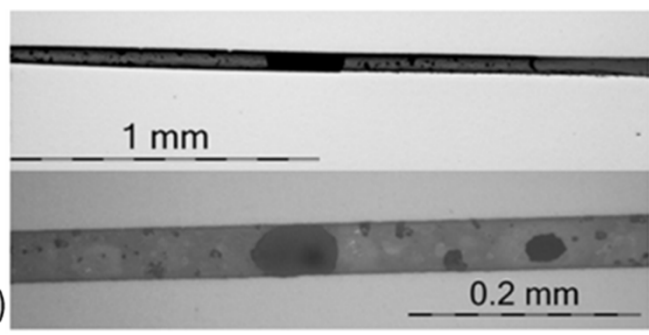

Figure 8. Microscope images of cross sections of the joining layers of type A (a) and type B (b). The parts were joined when the solders were in the wet state.

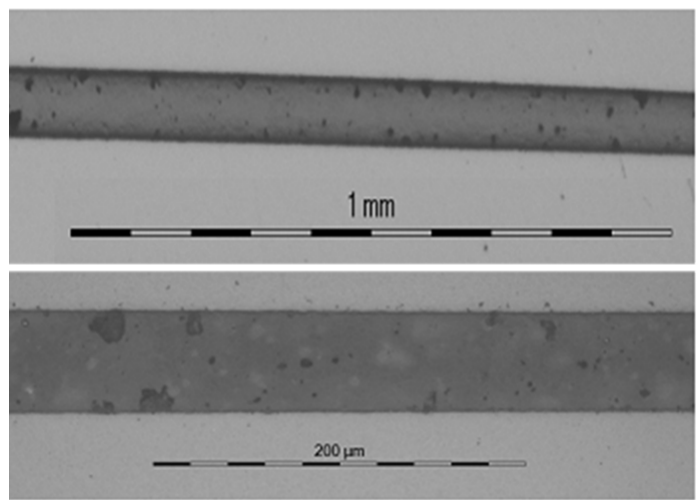

Figure 9. Microscope images of a cross section of the joining layers of type B. The parts were joined when the solder was in the dried state.

layer by a light optical microscope. Figure 8 shows microscope images of cross sections of joined layers for both types. The layers are mechanically stable even when they have been cut for inspection.

Type A exhibits many pores, with sizes ranging from 50 to $500 \mu \mathrm{m}$. Type B also shows many pores; however the number of big pores is reduced. Whether this can be attributed to the glass itself is not clear yet. Both glasses seem to be suitable to form a stable joint. Mainly due to its lower sintering temperature, type $\mathrm{B}$ was chosen for further investigation as this gives more freedom for different electrode materials.

In the second experiment, the type B binder was dried before joining the parts. With respect to flatness imperfections of the joining surfaces, the thickness of the glass solder was doubled by printing on both joining surfaces. The obtained

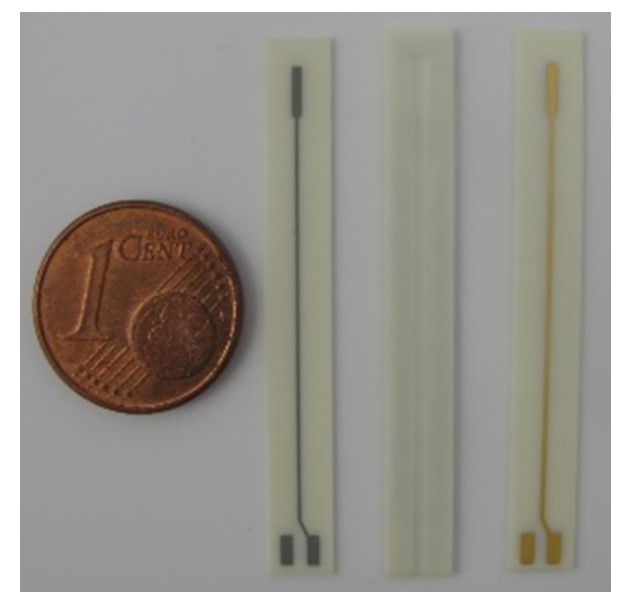

Figure 10. Heating element of a sensor with electrolyte with platinum and gold electrodes.

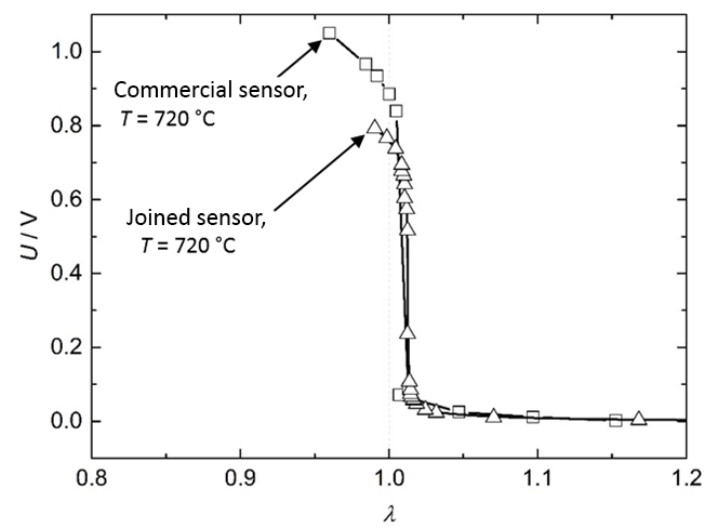

Figure 11. Sensor response of a commercial lambda probe and of the joined sensor. $\lambda$ was varied around the stoichiometric point and to some extent to lean exhaust.

sensor was checked for tightness by dye penetrant inspection.

As shown in Fig. 9, pores can be greatly reduced in number and size by drying the paste before joining the layers. The pore size is reduced for almost all pores to below $30 \mu \mathrm{m}$.

Figure 10 shows sintered parts ready for joining. The platinum electrode is standard for the HTCC process. The gold electrode, however, is only feasible for this design due to the newly developed joining process. Both electrodes can be joined with the heating element with the reference channel.

After the tightness of the joined sensor devices was confirmed by a dye impregnation test, measurements of glassjoined structures were conducted using the same setup as for the one-step sintered sensor. On the electrodes exposed to the test gas, the same platinum catalyst on alumina carrier as mentioned above was applied by brush coating (thickness about $100 \mu \mathrm{m}$ ) to enhance chemical equilibrium kinetics. The sensor response was compared with a commercial 
type lambda probe with respect to its sensitivity to lambda changes (at around the stoichiometric point at $\lambda=1$ ).

Both sensors were operated at approximately $720^{\circ} \mathrm{C}$. The sensor characteristics of the commercial lambda probe and the joined sensor are compared in Fig. 11. As in the case of the one-step sintered sensor, the lambda switch is clearly visible; the commercial type sensor and the joined sensor agree quite well. The lower values for the sensor voltage in rich gases may originate from the more advanced catalyst coating on the electrode of the commercial sensor.

\section{Conclusion}

In this study we show a method to manufacture a lowtemperature-joined lambda sensor. The initial step was to build a monolithic sensor. Special attention was given to the heater layout, where the design process was supported by means of FEM modeling. The resulting sensor showed a uniform temperature distribution in the range of $\pm 10^{\circ} \mathrm{C}$ at $660^{\circ} \mathrm{C}$. During manufacturing of the sensor, several key processes were found to be critical for reliability and were therefore improved. Vias have to be filled completely from one side, ensuring electrical connection. Roughness of the insulation layer is detrimental to the quality of the conduction paths; the reliability can be increased by printing wider conduction paths. At the area of the sensor where conduction paths have to cross the start of the insulation layer, additional paste has to be applied to prevent failure. Tests in gas atmospheres show that the monolithic sensor shows the desired binary lambda behavior. Later on, a low-temperature joining process was applied. It enabled us to seal tightly two parts of the YSZ sensor. Best results for tightness can be obtained if the solder is applied to the parts to be joined and dried before bonding them together. Tests at a gas test bench proved the functionality of the sensor.

It is now possible to vary the material of both electrodes on a switching-type lambda sensor. This may lead to many interesting prospects in future research and application as the variety of possible electrode materials increases drastically with the possibility of using materials with a sintering temperature as low as $850^{\circ} \mathrm{C}$.

\section{Edited by: H. Fritze}

Reviewed by: two anonymous referees

\section{References}

Alkemade, U. and Schumann, B.: Engines and exhaust after treatment systems for future automotive applications, Solid State Ionics, 177, 2291-2296, doi:10.1016/j.ssi.2006.05.051, 2006.

Badwal, S.: Zirconia-based solid electrolytes: microstructure, stability and ionic conductivity, Solid State Ionics, 52, 23-32, doi:10.1016/0167-2738(92)90088-7, 1992.

Baunach, T., Schänzlin, K., and Diehl, L.: Sauberes Abgas durch Keramiksensoren, Physik Journal, 5, 33-38, 2006.
Brosha, E.: Development of ceramic mixed potential sensors for automotive applications, Solid State Ionics, 148, 61-69, doi:10.1016/S0167-2738(02)00103-0, 2002.

Burke, L. E., Rickert, H., and Steiner R.: Elektrochemische Untersuchungen zur Teilleitfähigkeit, Beweglichkeit und Konzentration der Elektronen und Defektelektronen in dotiertem Zirkondioxid und Thoriumdioxid, Z. Phys. Chem. Neue. Fol., 74, 146167, 1971.

Dev, B., Walter, M. E., Arkenberg, G. B., and Swartz, S. L.: Mechanical and thermal characterization of a ceramic/glass composite seal for solid oxide fuel cells, J. Power Sources, 245, 958-966, doi:10.1016/j.jpowsour.2013.07.054, 2014.

ESL ElectroScience: Materials for planar oxygen sensors and other HTCC multilayer structures, available at: http://www. electroscience.com/sensormaterials.html, last access: 12 December 2015.

Fergus, J.: Materials for high temperature electrochemical $\mathrm{NO}_{x}$ gas sensors, Sensor Actuat. B-Chem., 121, 652-663, doi:10.1016/j.snb.2006.04.077, 2007.

Fischer, S., Pohle, R., Farber, B., Proch, R., Kaniuk, J., Fleischer, M., and Moos, R.: Method for detection of $\mathrm{NO}_{x}$ in exhaust gases by pulsed discharge measurements using standard zirconiabased lambda sensors, Sensor Actuat. B-Chem., 147, 780-785, doi:10.1016/j.snb.2010.03.092, 2010.

Guth, U. and Zosel, J.: Electrochemical solid electrolyte gas sensors - hydrocarbon and $\mathrm{NO}_{x}$ analysis in exhaust gases, Ionics, 10, 366-377, doi:10.1007/BF02377996, 2004.

Hagen, G., Burger, K., Wiegärtner, S., Schönauer-Kamin, D., and Moos, R.: A mixed potential based sensor that measures directly catalyst conversion - A novel approach for catalyst on-board diagnostics, Sensor Actuat. B-Chem., 217, 158-164, doi:10.1016/j.snb.2014.10.004, 2015a.

Hagen, G., Leupold, N., Wiegärtner, S., and Moos, R.: Sensor Tool for Fast Catalyst Material Light-off Characterization, CAPOC10 - 10th International Congress on Catalysis and Automotive Pollution Control, 28-30 October 2015, Brussels, Belgium, Vol. 2, 283-293, 2015b.

Imanaka, Y.: Multilayered Low Temperature Cofired Ceramics (LTCC) Technology, Springer, New York, USA, 2005.

Janek, J.: Electrochemical blackening of yttria-stabilized zirconia - morphological instability of the moving reaction front, Solid State Ionics, 116, 181-195, doi:10.1016/S0167-2738(98)004159, 1999.

Kato, N., Nakagaki, K., and Ina, N.: Thick film $\mathrm{ZrO}_{2} \mathrm{NO}_{x}$ sensor, SAE Technical Paper, 960334, doi:10.4271/960334, 1996.

Khoong, L. E., Tan, Y. M., and Lam, Y. C.: Overview on fabrication of three-dimensional structures in multi-layer ceramic substrate, J. Eur. Ceram. Soc., 30, 1973-1987, doi:10.1016/j.jeurceramsoc.2010.03.011, 2010.

Kita, J., Rettig, F., Moos, R., Drüe, K.-H., and Thust, H.: Hot Plate Gas Sensors-Are Ceramics Better?, Int. J. Appl. Ceram. Tec., 2, 383-389, doi:10.1111/j.1744-7402.2005.02037.x, 2005.

Kita, J., Engelbrecht, A., Schubert, F., Groß, A., Rettig, F., and Moos, R.: Some practical points to consider with respect to thermal conductivity and electrical resistivity of ceramic substrates for high-temperature gas sensors, Sensor Actuat. B-Chem., 213, 541-546, doi:10.1016/j.snb.2015.01.041, 2015. 
Lessing, P. A.: A review of sealing technologies applicable to solid oxide electrolysis cells, Journal of Material Science, 42, 34653476, doi:10.1007/s10853-006-0409-9, 2007.

Liu, Y., Parisi, J., Sun, X., and Lei, Y.: Solid-state gas sensors for high temperature applications - a review, J. Mater. Chem., 2, 9919, doi:10.1039/C3TA15008A, 2014.

Mahendraprabhu, K., Miura, N., and Elumalai, P.: Temperature dependence of NO2 sensitivity of YSZ-based mixed potential type sensor attached with $\mathrm{NiO}$ sensing electrode, Ionics, 19, 16811686, doi:10.1007/s11581-013-0894-1, 2013.

Ménil, F., Coillard, V., and Lucat, C.: Critical review of nitrogen monoxide sensors for exhaust gases of lean burn engines, Sensor Actuat. B-Chem., 67, 1-23, doi:10.1016/S0925-4005(00)004019, 2000.

Miura, N., Lu, G., and Yamazoe, N.: High-temperature potentiometric/amperometric $\mathrm{NO}_{x}$ sensors combining stabilized zirconia with mixed-metal oxide electrode, Sensor Actuat. B-Chem., 52, 169-178, doi:10.1016/S0925-4005(98)00270-6, 1998.

Miura, N., Sato, T., Anggraini, S. A., Ikeda, H., and Zhuiykov, S.: A review of mixed-potential type zirconia-based gas sensors, Ionics, 20, 901-925, doi:10.1007/s11581-014-1140-1, 2014.

Moos, R., Sahner, K., Fleischer, M., Guth, U., Barsan, N., and Weimar, U.: Solid state gas sensor research in Germany - a status report, Sensors, 9, 4323-4365, doi:10.3390/s90604323, 2009.

Ortolino, D., Kita, J., Wurm, R., Blum, E., Beart, K., and Moos, R.: Investigation of the short-time high-current behavior of vias manufactured in hybrid thick-film technology, Microelectron. Reliab., 51, 1257-1263, doi:10.1016/j.microrel.2011.02.025, 2011.

Rabe, T., Kuchenbecker, P., Schulz, B., and Schmidt, M.: Hot Embossing: An Alternative Method to Produce Cavities in Ceramic Multilayer, Int. J. Appl. Ceram. Tec., 4, 38-46, doi:10.1111/j.1744-7402.2007.02117.x, 2007.

Ramamoorthy, R., Dutta, P. K., and Akbar, S. A.: Oxygen sensors: Materials, methods, designs and applications, J. Mater. Sci., 38, 4271-4282, doi:10.1023/A:1026370729205, 2003.

Riegel, J.: Exhaust gas sensors for automotive emission control, Solid State Ionics, 152-153, 783-800, doi:10.1016/S01672738(02)00329-6, 2002.
Schönauer, D., Nieder, T., Wiesner, K., Fleischer, M., and Moos, R.: Investigation of the electrode effects in mixed potential type ammonia exhaust gas sensors, Solid State Ionics, 192, 38-41, doi:10.1016/j.ssi.2010.03.028, 2011.

Tanaka, H., Sawai, S., Morimoto, K., and Hisano, K.: Measurement of Spectral Emissivity and Thermal Conductivity of Zirconia by Thermal Radiation Calorimetry, J. Therm. Anal. Calorim., 64, 867-872, doi:10.1023/A:1011538022439, 2001.

Twigg, M. V.: Progress and future challenges in controlling automotive exhaust gas emissions, Appl, Catal. B-Environ., 70, 2-15, doi:10.1016/j.apcatb.2006.02.029, 2007.

VDI Heat Atlas, 2nd ed, VDI-Buch, Springer, Berlin, Germany and London, UK, 2010.

Wang, D. Y., Yao, S., Shost, M., Yoo, J.-H., Cabush, D., Racine, D., Cloudt, R., and Willems, F.: Ammonia Sensor for Closed-Loop SCR Control, SAE Int. J. Passeng. Cars - Electron. Electr. Syst., 1, 323-333, doi:10.4271/2008-01-0919, 2009.

Wang, D., Racine, D., Husted, H., and Yao, S.: Sensing Exhaust $\mathrm{NO}_{2}$ Emissions Using the Mixed Potential Principle, SAE Paper 2014-01-1487, 2014, doi:10.4271/2014-01-1487, 2014.

Xiong, W. and Kale, G. M.: Novel high-selectivity NO2 sensor incorporating mixed-oxide electrode, Sensor Actuat. B-Chem., 114, 101-108, doi:10.1016/j.snb.2005.04.010, 2006.

Zhuiykov, S. and Miura, N.: Development of zirconia-based potentiometric $\mathrm{NO}_{x}$ sensors for automotive and energy industries in the early 21 st century: What are the prospects for sensors?, Sensor Actuat. B-Chem., 121, 639-651, doi:10.1016/j.snb.2006.03.044, 2007.

Zosel, J., Westphal, D., Jakobs, S., Müller, R., and Guth, U.: Auoxide composites as $\mathrm{HC}$-sensitive electrode material for mixed potential gas sensors, Solid State Ionics, 152-153, 525-529, doi:10.1016/S0167-2738(02)00355-7, 2002.

Zosel, J., Ahlborn, K., Müller, R., Westphal, D., Vashook, V., and Guth, U.: Selectivity of HC-sensitive electrode materials for mixed potential gas sensors, Solid State Ionics, 169, 115-119, doi:10.1016/S0167-2738(03)00082-1, 2004. 